\title{
HUBUNGAN KEPERCAYAAN DIRI IBU DENGAN PERKEMBANGAN ANAK USIA PRA SEKOLAH
}

\author{
Selpina Embuai*, Moomina Siauta \\ Fakultas Kesehatan, Universitas Kristen Indonesia Maluku, Jln Ot Pattimaipauw, Talake Kecamatan, Nusaniwe, Kel \\ Wainitu, Nusaniwe, Kota Ambon, Maluku, Indonesia, 97115 \\ *selfiembuai@gmail.com
}

\begin{abstract}
ABSTRAK
Ibu memiliki peranan yang sangat penting dalam setiap tahap perkembangan anak. Gangguan perkembangan bicara dan bahasa dialami oleh $8 \%$ anak usia prasekolah. Kepercayaan ibu akan kemampuannya untuk merawat anak-anaknya sangatlah diperlukan. Akibat dari kurangnya kepercayaan diri ibu akan mempengaruhi perkembangan anaknya. Tujuan penelitian adalah diketahuinya hubungan kepercayaan diri ibu dengan perkembangan anak usia prasekolah di Kelurahan Benteng Kecamatan Nusaniwe Kota Ambon. Metode : Jenis penelitian adalah cross sectional. Populasinya adalah seluruh anak prasekolah di kelurahan benteng dengan jumlah sampel sebesar 107 orang. Teknik pengambilan sampel dilakukan dengan cara purposive sampling. Uji yang digunakan adalah Chi Square. Instrumen yang digunakan adalah kuesioner yang telah diuji validitas dan reliabilitasnya. Hasil Penelitian menunjukkan bahwa jumlah ibu yang memiliki kepercayaan diri yang tinggi (50.5\%) juga memiliki anak dengan tingkat perkembangan yang normal (61.7\%). Hasil penelitian juga menunjukkan bahwa adanya hubungan antara kepercayaan diri ibu dengan perkembangan anak usia prasekolah $(\mathrm{p}=0.001)$. Kepercayaan diri ibu memiliki peranan penting dan sangat berpengaruh terhadap perkembangan anak usia pra sekolah.
\end{abstract}

Kata kunci: anak usia pra sekolah, kepercayaan diri ibu, perkembangan anak, anak usia pra sekolah

\section{THE RELATIONSHIP BETWEEN MOTHER CONFIDENCE WITH DEVELOPMENT OF PRE-SCHOOL AGE CHILDREN}

\begin{abstract}
Mothers have a very important role in each stage of child development. Speech and language developmental disorders are experienced by $8 \%$ of preschool age children. A mother's trust in her ability to care for her children is needed. As a result of lack of confidence in the mother will affect the development of their children. The purpose of this study was to determine the relationship of maternal confidence with the development of preschool age children in Benteng Subdistrict, Nusaniwe Subdistrict, Ambon City. Method: This type of research is cross sectional. The population is all preschool children in Benteng village with a total sample of 107 people. The sampling technique is done by purposive sampling. The test used is Chi Square. The instrument used was a questionnaire that had been tested for validity and reliability. The results showed that the number of mothers who had high self-confidence (50.5\%) also had children with normal developmental levels (61.7\%). The results also showed that there was a relationship between maternal confidence with the development of preschool children $(p=0.001)$. Mother's confidence has an important role and is very influential in the development of pre-school age children.
\end{abstract}

Keywords: child development,, mother's confidence, pre-school age children.

\section{PENDAHULUAN}

Keluarga adalah unit terkecil dari masyarakat yang terdiri dari suami, istri atau suami istri dan anaknya atau ayah dan anaknya atau ibu dan anaknya (Dion, 2013). Keluarga memiliki peranan yang sangat penting dalam setiap tahap perkembangan anggota keluarga. Setiap anggota keluarga mempunyai peranan masing-masing. Selain sebagai pengurus rumah tangga, peranan ibu juga adalah sebagai pengasuh, pendidik, pelindung dan pencari nafkah tambahan bagi keluarga (Dion, 2013). Menurut Suryani (2008), seorang ibu memiliki peranan yang sangat besar dalam perkembangan anak-anaknya karena ibu memiliki ikatan psikologis yang sangat kuat. Selain itu juga ibu merupakan lingkungan pertama dan utama bagi seorang anak. Jadi perkembangan anak sangat bergantung terhadap peran dari seorang ibu (Saleh, 2011).

Terdapat 8 tahap perkembangan keluarga. Salah satu diantaranya adalah keluarga dengan anak usia pra sekolah. Tugas perkembangannya adalah menyesuaikan pada kebutuhan anak pra sekolah 
(sesuai dengan tumbuh kembang, proses belajar dan kontak social). Tumbuh kembang anak terdiri dari beberapa tahapan dimana setiap tahapan mempunyai ciri masing-masing. Salah satu tahapan tumbuh kembang anak adalah usia prasekolah (Wong, 2003).

Keterlambatan bicara pada anak adalah salah satu kelainan yang sering dialami oleh anak-anak dan terjadi pada 1 dari 12 anak atau 5-8\% dari anakanak prasekolah. Sekitar $8 \%$ dari 9,4 juta anak Indonesia mengalami keterlambatan bicara dan bahasa. Keterlambatan sering terjadi pada usia 316 tahun. Pada anak usia 5 tahun, 19\% diidentifikasi memiliki gangguan bicara dan bahasa $(6,4 \%$ keterlambatan bicara, $4,6 \%$ keterlambatan bicara dan bahasa, dan 6\% keterlambatan bahasa). Gagap terjadi 4-5\% pada anak usia 3-5 tahun. Keterlambatan perkembangan awal kemampuan bahasa dapat mempengaruhi sebagai fungsi dalam kehidupan sehari-hari. Selain mempengaruhi kehidupan personal sosial, juga akan menimbulkan kesulitan belajar, kesulitan membaca, dan gangguan prestasi akademik termasuk penurunan prestasi di sekolah sampai drop out (Fajrah, 2017) .

Studi Cochrane terakhir telah melaporkan data keterlambatan bicara, bahasa dan gabungan keduanya pada anak usia prasekolah dan usia sekolah. Prevalensi keterlambatan perkembangan bahasa dan bicara pada anak usia 2 sampai 4,5 tahun adalah 5-8\%, prevalensi keterlambatan perkembangan bahasa adalah 2,3-19\%. Sebagian besar studi melaporkan prevalensi dari $40 \%$ sampai $60 \%$. Prevalensi keterlambatan perkembangan berbahasa di Indonesia belum pernah diteliti secara luas. Kendalanya dalam menentukan kriteria keterlambatan perkembangan berbahasa. Data di Departemen Rehabilitasi Medik RSCM, dari 1125 jumlah kunjungan pasien anak terdapat $10,13 \%$ anak terdiagnosis keterlambatan bicara dan bahasa (Depkes, 2016). Menurut Departemen kesehatan, didapati bahwa anak-anak Indonesia unggul dalam hal komunikasi dan pengetahuan umum, serta kompetensi sosial, tetapi memiliki kelemahan dalam hal keterampilan yang berkaitan dengan baca tulis dan perkembangan kognitif (Depkes, 2016).

Data dari Puskesmas Air Salobar kota Ambon tercatat ada 438 jumlah anak usia pra sekolah di kelurahan Benteng kecamatan Nusaniwe kota Ambon. Program tumbuh kembang telah dijalankan di puskesmas Air Salobar selama kurun waktu \pm 5 tahun. Dari data menunjukan
$100 \%$ tidak ada masalah dengan pertumbuhan anak usia pra sekolah. Untuk data perkembangan tidak tercatat sehingga data untuk penilaian status perkembangan anak usia pra sekolahpun tidak ada

Seperti yang telah dijelaskan sebelumnya, orang tua khususnya ibu, merupakan lingkungan yang pertama dan utama bagi seorang anak. Peran seorang ibu sangat penting, terutama sebagai agen kesehatan bagi anak dan keluarga dalam upaya memenuhi kebutuhan asah, asuh, asih pada anak. Oleh karena itu, setiap ibu yang memiliki anak memerlukan pengetahuan, sikap dan keterampilan yang benar serta memiliki kepercayaan diri yang tinggi tentang hal tersebut (Saleh, 2011). Menurut penelitian yang dilakukan oleh Harrison, perawat memiliki pengaruh yang sangat besar dalam upaya meningkatkan kepercayaan diri ibu yang erat kaitannya dengan perkembangan anak-anaknya. Menjadi seorang ibu adalah salah satu peran sosial yang paling penting dalam kehidupan. Kepercayaan ibu akan kemampuannya untuk merawat anak-anaknya sangatlah diperlukan. Akibat dari kurangnya kepercayaan diri ibu akan mempengaruhi perkembangan anaknya (Kurniawati, Rosra, \& Utaminingsih, 2017).

Banyak penelitian yang telah dilakukan untuk menilai tumbuh kembang anak serta program dari dinas kesehatan Kota Ambon yang telah dilakukan untuk mengidentifikasi tumbuh kembang anak berbagai usia, termasuk anak usia pra sekolah dalam rangka pencapaian status gizi yang maksimal. Namun yang terkait dengan hubungan kepercayaan diri ibu yang bisa mempengaruhi perkembangan dari anak usia pra sekolah belum pernah dilakukan sebelumnya. Tujuan dari penelitian ini adalah untuk mengetahui hubungan kepercayaan diri ibu dengan perkembangan anak usia pra sekolah.

\section{METODE}

Desain penelitian yang digunakan adalah deskriptif dengan menggunakan pendekatan cross sectional Penelitian ini dilakukan selama 1 bulan (Juli - Agustus) pada tahun 2017 di Kelurahan Benteng, Kota Ambon. Jumlah responden dalam penelitian ini sebanyak 107 meliputi ibu dan anak. Teknik sampling dengan purposive sampling. Instrument yang digunakan adalah kuesioner kepercayaan diri ibu yang telah diuji validitas dan reliabilitasnya dan didapatkan 30 item pertanyaan yang sesuai dengan nilai $r$ Alpha untuk instrumen kepercayaan diri ibu adalah 0,857 serta format Denver Developmental Skrining test II (DDST II). Uji yang digunakan adalah chi-square test. 


\section{HASIL}

Hasil penelitian yang dilakukan peneliti dapat dilihat pada tabel berikut.

Tabel 1.

Karakteristik responden berdasarkan tingkat pendidikan, umur, pekerjaan $(\mathrm{n}=107)$

\begin{tabular}{lcc}
\hline \multicolumn{1}{c}{ Variabel } & $\mathrm{f}$ & $\%$ \\
\hline Tingkat pendidikan & 3 & 2.8 \\
SMP & 104 & 97.2 \\
SMA & 107 & 100 \\
Umur & & 100 \\
$\begin{array}{l}\text { Pekerjaan } \\
\text { Ibu rumah tangga }\end{array}$ & 107 & 100 \\
\hline
\end{tabular}

Hasil penelitian menunjukkan mayoritas responden berpendidikan terakhir SMA, seluruhnya berusia 20-35 tahun dan sebagai ibu rumah tangga.

Tabel 2.

Kepercayaan diri ibu $(\mathrm{n}=107)$

\begin{tabular}{lccc}
\hline & Variabel & f & $\%$ \\
\hline Kepercayaan diri ibu & & 54 & 50.5 \\
Tinggi & 53 & 49.5 \\
Rendah & & 53 & \\
\hline
\end{tabular}

Hasil penelitian menunjukkan mayoritas

kepercayaan ibu tinggi.

Tabel 3.

Perkembangan Anak Usia Pra Sekolah $(\mathrm{n}=107)$

\begin{tabular}{lll}
\hline \multicolumn{1}{c}{ Variabel } & f & $\%$ \\
\hline Perkembangan anak usia pra sekolah & & \\
Normal & 66 & 61.7 \\
Suspek & 41 & 38.3 \\
\hline
\end{tabular}

Hasil penelitian menunjukkan mayoritas

perkembangan anak usia pra sekolah pada tahap

normal.

Tabel 4.

Analisis hubungan kepercayaan diri ibu dengan perkembangan anak usia pra sekolah $(n=107)$

\begin{tabular}{|c|c|c|c|c|c|c|}
\hline \multirow{3}{*}{$\begin{array}{c}\text { Kepercayaan Diri } \\
\text { Ibu }\end{array}$} & \multicolumn{4}{|c|}{ Perkembangan Anak } & \multirow{2}{*}{ Jumlah } & \multirow[b]{2}{*}{$p$} \\
\hline & \multicolumn{2}{|c|}{ Normal } & \multicolumn{2}{|r|}{ Suspek } & & \\
\hline & $\mathrm{f}$ & $\%$ & $f$ & $\%$ & $\%$ & \\
\hline Tinggi & 25 & 46.3 & 29 & 53.7 & 100.0 & 0.001 \\
\hline Rendah & 41 & 77.4 & 12 & 22.6 & 100.0 & \\
\hline \multicolumn{4}{|c|}{$\begin{array}{l}\text { Hasil analisis menunjukkan ada hubungan } \\
\text { kepercayaan diri ibu dengan perkembangan anak } \\
\text { usis pra sekolah }(\mathrm{p} \text { value }=0,001) \text {. }\end{array}$} & \multicolumn{3}{|c|}{$\begin{array}{l}\text { distribusi karakteristik } \text { responden } \text { (tingkat } \\
\text { pendidikan, usia, dan pekerjaan) dijabarkan } \\
\text { sebagai berikut: } \\
\text { Usia }\end{array}$} \\
\hline \multicolumn{4}{|c|}{$\begin{array}{l}\text { PEMBAHASAN } \\
\text { Karakteristik responden } \\
\text { Karakteristik ibu merupakan salah satu konsep } \\
\text { teori keperawatan Maternal Role Attainment yang } \\
\text { mempengaruhi pencapaian peran menjadi seorang } \\
\text { ibu (Husmillo, 2013). Menurut Warren, faktor- } \\
\text { faktor yang mempengaruhi kepercayaan diri ibu } \\
\text { adalah usia, tingkat pendidikan dan pekerjaan. } \\
\text { Hasil penelitian berdasarkan tabel } 1 \text { mengenai }\end{array}$} & \multicolumn{3}{|c|}{$\begin{array}{l}\text { Hasil penelitian menunjukan distribusi responden } \\
\text { berdasarkan umur menunjukan seluruh responden } \\
\text { berada pada rentang usia 20-35 tahun. Hal ini juga } \\
\text { sejalan dengan penelitian yang dilakukan oleh } \\
\text { Ruchala dan James (dikutip dalam Saleh) terhadap } \\
\text { ibu yang masih remaja dengan yang dewasa. Hasil } \\
\text { penelitian menunjukan bahwa ibu yang dewasa } \\
\text { memiliki tingkat pengetahuan yang lebih tinggi } \\
\text { mengenai perkembangan anaknya dibandingkan }\end{array}$} \\
\hline
\end{tabular}


dengan ibu remaja. Semakin dewasa umur seseorang maka semakin banyak pengalaman dan informasi yang diperoleh sehingga dapat membangun konsep yang baik yang mampu menumbuhkan kepercayaan diri dalam melakukan segala sesuatu (Saleh, 2011).

\section{Tingkat pendidikan}

Hasil penelitian menunjukan distribusi responden berdasarkan tingkat pendidikan yaitu jumlah responden lebih banyak tamatan SMU yaitu 104 responden (97. 2\%) dan tamatan SMP 3 responden (2.8\%). Berdasarkan teori yang dikemukakan oleh Wong, bahwa pendidikan dan pengalaman orang tua dalam perawatan anak akan mempengaruhi kesiapan mereka dalam peran pengasuhan (Wong, 2003). Sama halnya dengan teori yang dikemukan oleh Mercer, bahwa faktor karakteristik maternal termasuk pengetahuan dan tingkat pendidikan merupakan faktor yang penting dalam teori Maternal Role Attainment (Mercer, 2004).

Menurut Maryam (2017) Bagi ibu walaupun pendidikan merupakan salah satu hal penting dalam kehidupan, yang harus dimiliki setiap orang dan digunakan dalam mengasuh dan membina keturunanya. Dengan demikian bagi ibu dengan pendidikan diharapkan dapat selalu meningkatkan pengetahuan dan wawasan dalam pengasuhan anak yang baik yaitu pola asuh demokratis sehingga keterlambatan perkembangan anak dapat diketahui sedini mungkin dan dapat segera dikonsultasikan ke tenaga kesehatan sehingga menjadikan perkembangan anak menjadi optimal. Karena dengan pola pengasuhan yang baik akan menentukan perkembangan anak selanjutnya (Maryam, 2017).

Menurut Wadikil dan Adini (2016), yang menjelaskan bahwa Pendidikan ibu tidak berhubungan langsung dengan pertumbuhan dan perkembangan anak. Pendidikan ibu melalui mekanisme hubungan lain seperti produktivitas, efisiensi penjagaan kesehatan mempengaruhi pertumbuhan dan perkembangan anak secara tidak langsung (Waqidil H \& Ck, 2016). Menurut Monk dikutip dalam Saleh (2012), juga mengungkapkan bahwa tingkat pengetahuan seseorang mempengaruhi kepercayaan dirinya. Semakin tinggi tingkat pengetahuan individu sehingga dapat mengenal diri dengan baik kekurangan maupun kelebihannya sehingga mampu menentukan sendiri standar keberhasilannya. Teori ini juga sejalan dengan penelitian yang dilakukan oleh Piwoz dikutip dalam Saleh (2012) bahwa tingkat pengetahuan seseorang yang semakin tinggi akan berdampak pada perkembangan ke arah yang lebih baik sehingga ibu yang berpengetahuan yang baik akan lebih objektif dan terbuka wawasannya dalam mengambil suatu keputusan atau tindakan yang diaplikasikan dengan perilaku positif terutama dalam memberikan stimulasi terhadap pertumbuhan dan perkembangan anaknya (Saleh, 2011). Berdasarkan teori dan hasil penelitian yang dipaparkan dapat ditarik kesimpulan bahwa tingkat pendidikan secara tidak langsung mempengaruhi orang tua dalam hal perawatan dan pengasuhan terhadap anak-anaknya. Ibu dengan tingkat pendidikan yang baik akan semakin terbuka wawasannya dalam menstimulasi tumbuh kembang anaknya.

\section{Pekerjaan}

Hasil penelitian menunjukan distribusi responden berdasarkan pekerjaan menunjukkan bahwa semua responden berprofesi sebagai ibu rumah tangga yaitu 107 responden (100\%). Menurut Soetjiningsih, bahwa pendapatan yang memadai akan menunjang pertumbuhan dan perkembangan anak. Tingkat pendapatan yang memadai akan memberikan kemungkinan yang lebih besar pada ibu untuk menyediakan semua kebutuhan anak baik primer maupun sekunder sehingga dapat memfasilitasi perkembangan anak (Soetjiningsih, 2013). Menurut Saleh, peningkatan pendapatan memungkinkan keluarga untuk membeli makanan yang cukup, menggunakan pelayanan kesehatan lebih sering dan dengan kualitas memadai, meningkatkan kesehatan lingkungan dan memperoleh pendidikan yang lebih baik, sehingga meningkatkan kemampuannya untuk berperilaku gizi dan kesehatan yang baik (Saleh, 2011). Berdasarkan apa yang telah dipaparkan diatas, dapat ditarik kesimpulan bahwa pekerjaan selalu dihubungkan dengan pendapatan seseorang. Semakin baik pendapatan ibu, maka akan memberikan kemungkinan untuk memenuhi kebutuhan tumbuh kembang anak secara maksimal.

\section{Kepercayaan diri ibu}

Berdasarkan hasil penelitian pada tabel 2 mengenai distribusi responden berdasarkan kepercayaan diri ibu menunjukkan bahwa hampir berimbang antara kepercayaan diri ibu yang tinggi (50.5\%) dan kepercayaan diri ibu yang rendah (49.5\%). Hal ini sesuai dengan teori yang diungkapkan oleh Mercer dan Walker, bahwa konsep keperawatan Maternal Role Attainment merupakan upaya yang dilakukan untuk meningkatkan kepercayaan diri dan efikasi diri ibu (Mercer, 2004). Mercer dan Walker juga 
mengatakan bahwa kepercayaan diri ibu merupakan variabel penting dalam adaptasi ibu dan peran maternal. Maternal Role Identity dalam teori Maternal Role Attainment melibatkan komponen afektif dan perilaku. Komponen afektif dikaitkan dengan perasaan perasaan subjektif ibu tentang kemampuan merawat anaknya (Mercer, 2004).

Penelitian yang dilakukan oleh Saleh, ditujukan untuk meningkatkan percaya diri ibu yang selanjutnya dapat meningkatkan motifasi ibu dalam menstimulasi tumbuh kembang anaknya (Saleh, 2011). Sama halnya dengan yang diungkapkan oleh Russel dalam penelitiannya bahwa kepercayaan diri ibu adalah komponen peran maternal diartikan sebagai persepsi ibu terhadap kemampuannya dalam merawat dan memahami anak-anaknya. Kepercayaan diri maternal adalah persepsi ibu akan kemampuannya merawat anak dan merasa puas menjalankan perannya sebagai seorang ibu. Kepercayaan diri merupakan refleksi kompetensi ibu, kemampuan maternal ini dipengaruhi oleh beberapa variabel antara lain pengetahuan, ketrampilan, status psikososial, karakteristik ibu, dukungan social serta karakteristik dan sifat anak (Saleh, 2011).

Menurut Gerugan, interaksi sosial dapat berdampak pada peningkatan kepercayaan diri seseorang. Interaksi social merupakan suatu proses dimana individu memperhatikan dan merespon individu lain, sehingga dibalas dengan respon tertentu pula. Pada interaksi antara ibu dan keluarga yang merupakan orang yang terdekat dengan ibu akan saling mempengaruhi satu sama lain. Kaitannya dengan rasa percaya diri adalah bagaimana interaksi social tersebut dapat mendukung ibu sehingga menimbulkan pandangan positif dan rasa percaya diri dalam merawat anak (Saleh, 2011). Sama halnya dengan penelitian yang dilakukan oleh (Henney, 2016) tentang The Relationship Between Personality and Parental Confidence in Mothers of School Aged Children. Studi ini mengeksplorasi hubungan antara kepribadian dan kepercayaan orang tua terhadap anak-anak usia sekolah. Hubungan antara kepribadian dan kompetensi pengasuhan anak dan juga antara kepercayaan orang tua dan kemampuan pola asuh menemukan bahwa kontrol diri dan kemandirian yang lebih tinggi mempengaruhi kepercayaan diri ibu sedangkan Kecemasan mempengaruhi kepercayaan diri ibu dalam melakukan pola asuh anak. Berdasarkan apa yang telah dipaparkan diatas, dapat ditarik kesimpulan, bahwa kepercayaan diri seorang ibu dipengaruhi oleh beberapa factor seperti pengetahuan, dukungan social, interaksi sosial serta identitas maternal.

\section{Perkembangan anak usia pra sekolah}

Hasil penelitian pada tabel 3 mengenai distribusi responden berdasarkan perkembangan anak usia pra sekolah menunjukkan bahwa lebih dari setengah responden (anak) memiliki tahap perkembangan yang normal (61.7\%), yang suspek sebanyak 41 responden (38.3\%). Anak dengan tahap perkembangan suspek, paling banyak mengalami keterlambatan pada sektor personal sosial dengan 20 kegagalan dan 10 keterlamatan pada pemeriksaan Denver II. Menurut Wong, perkembangan adalah perubahan dan perluasan secara bertahap, perkembangan kompleksitas dari yang lebih rendah ke yang lebih tinggi, peningkatan dan perluasan kapasitas seseorang melalui pertumbuhan, maturasi serta pembelajaran. Tugas perkembangan adalah serangkaian ketrampilan dan kompetensi yang harus dicapai atau dikuasai pada setiap tahap perkembangan agar anak mampu berinteraksi secara efektif dengan lingkungannya (Wong, 2003). Periode pra sekolah merupakan saat perkembangan fisik dan kepribadian yang besar. Perkembangan motorik berlangsung terus menerus, anak-anak pada usia ini membutuhkan bahasa dan hubungan social yang lebih luas, mempelajari standar peran, memperoleh kontrol dan penguasaan diri, semakin menyadari sifat ketergantungan dan kemandirian, dan mulai membentuk konsep diri (Wong, 2003).

Hasil riset dari Dinas Kesehatan tentang perkembangan anak di Indonesia menunjukan bahwa pada anak-anak usia 5 tahun (pra sekolah) diidentifikasi memiliki gangguan perkembangan bicara dan bahasa $(6,4 \%$ keterlambatan berbicara, 4,6\% keterlambatan bicara dan bahasa, dan $6 \%$ keterlambatan bahasa). Sedangkan studi Cochrane melaporkan data keterlambatan perkembangan bahasa dan bicara pada anak usia 2 - 4,5 tahun adalah 5 - 8\% (Depkes, 2016). Perkembangan anak usia prasekolah berada dalam fase perkembangan kepribadian yang besar. Mereka membutukan bahasa, dan hubungan social yang lebih luas. Namun hasil riset yang dilakukan menunjukan perlu adanya penanganan yang lebih lagi dari pemerintah mengenai masalah ganggungan perkembangan yang terjadi pada anak-anak usia prasekolah.

\section{Hubungan kepercayaan diri ibu dengan perkembangan anak usia pra sekolah}

Hasil penelitian pada tabel 4 mengenai Analisis hubungan kepercayaan diri ibu dengan 
perkembangan anak teridentifikasi Dari hasil uji statistik (chi-square) menunjukkan bahwa ada hubungan antara kepercayaan diri ibu dengan perkembangan anak karena nilai $\mathrm{p}=0.001(\mathrm{p}<$ 0.05). dari hasil penelitian juga dengan uji statistik didapatkan, hampir berimbang antara ibu dengan kepercayaan diri tinggi dengan tahap perkembangan anak normal ataupun suspek. Sementara ibu dengan kepercayaan diri rendah, tahap perkembangan anak yang normal lebih tinggi dari ibu dengan kepercayaan diri tinggi. hasil penelitian ini sejalan dengan teori yang diungkapkan oleh Mercer, tentang teori Maternal Role Attainment (Pencapaian peran ibu). Teori ini merupakan salah satu dari Middle Range Theory yang berfokus pada ibu dalam mengembangkan perannya sebagai seorang ibu agar lebih confidence (percaya diri) dalam melakukan perawatan anak-anaknya sehingga dapat mengoptimalisasi tumbuh kembang anaknya (Mercer, 2004).

Middle range theory, bukan hanya Maternal role attainment yang berpengaruh dalam mengembangkan peran ibu agar lebih confidence dalam menstimulasi anaknya. Ada juga Mother characterize (karakteristik ibu) yang meliputi empati, sensitiftas, self esteem, konsep diri, persepsi dan pengalaman melahirkan, fleksibilitas, status kesehatan ibu dan konflik peran. Selain itu terdapat juga infant characterize (karakteristik bayi) meliputi temperamen, penampilan, isyarat dan status kesehatan bayi. Serta faktor pendukung lain yaitu keluarga. Jadi walaupun ibu telah confidence belum tentu memilki anak dengan tahap perkembangan yang normal karena masih ada beberapa faktor yang turut berperan dalam stimulus perkembangan anak (Hushmillo, 2013).

Peran menjadi orang tua adalah salah satu peran sosial yang paling menuntut dan paling kuat yang dilakukan dalam hidup mereka. Keyakinan orangtua tentang seberapa baik kemampuan mereka menjadi orangtua merupakan komponen yang diperlukan untuk memahami bagaimana keyakinan mereka, perilaku pengasuhan yang sebenarnya, dan interaksi antara orang tua dan anak. Seberapa percaya diri orang tua menganggap diri karena dampak keyakinan pengasuhan ini dapat berdampak pada kesehatan dan perkembangan anak-anak. Keyakinan individu pada kemampuan mereka dalam peran pengasuhan sebagai orang tua yaitu, kepercayaan diri adalah komponen penting dari kualitas dan keberlanjutan perilaku pengasuhan dan perkembangan anak (Vance \& Brandon, 2017).
Peran menjadi seorang ibu adalah salah satu peran paling mendasar dan penting yang diperankan oleh wanita selama masa hidup mereka dan kepercayaan diri ibu telah dianggap sebagai variabel mendasar untuk memainkan peran sebagai ibu (Fasanghari, Kordi, \& Asgharipour, 2019). Wanita dengan tingkat kepercayaan diri yang tinggi memiliki tingkat kecemasan yang relative lebih rendah sehingga dengan cepat dapat berperan sebagai ibu. Ibu dengan tingkat kepercayaan diri yang tinggi memiliki tanggung jawab rumah tangga, sosial dan kegiatan komunitas, perawatan dan tumbuh kembang anak serta perawatan diri yang lebih baik dibandingkan dengan ibu yang memiliki tingkat kepercayaan diri yang rendah (Shafaie, Mirghafourvand, \& Bagherinia, 2017).

Penelitian yang dilakukan oleh (Mouton \& Roskam, 2015) tentang Confident Mothers, Easier Children: A Quasi-experimental Manipulation of Mothers' Self-efficacy menunjukkan bahwa ibu yang memiliki self-efficacy yang kuat, memiliki perilaku pengasuhan yang lebih positif terhadap anak-anaknya. Anak dengan ibu yang memiliki self-efficacy yang baik memiliki perkembangan yang baik. Penelitian ini membahas sifat kausal yang cukup kompleks dari hubungan antara kemanjuran diri orang tua, pola asuh dan perilaku anak.

Secara fisiologis dapat dihubungkan antara kepercayaan diri ibu yang dapat mempengaruhi perkembangan anak. Kepercayaan diri dipengaruhi oleh beberapa factor eksternal seperti lingkungan keluarga maupun lingkungan sosial. Semua yang didengar maupun yang dilihat akan dihantarkan melalui saraf yang dilaluinya. Misalnya sesuatu yang didengar akan dhantarkan oleh nervus VIII (auditorik) masuk ke tempat akustik intermediate. Selanjutnya di arahkan ke nucleus olivari superior lalu ke nucleus lemniskus lateralis selanjutnya ke kolikulus inferior lalu ke nucleus genikulatum dan masuk ke korteks auditorik primer di korteks serebri. Fungsi area asosiasi auditorik berhubungan dengan fungsi intelektual otak. Selanjutnya area asosiasi auditorik akan merangsang neurokorteks temporal dan oksipital selanjutnya akan merangsang amigdala. Amigdala adalah system limbic yang behubungan dengan alam sekitar dan juga pikiran. Di amigdala tepatnya dibagian nuclei basolateral akan membuat respon perilaku seseorang sesuai dengan tipa keadaan. Dari amigdala berlanjut ke area kortikal kemudian ke hipokampus. Hipokampus adalah sekumpulan neuron yang mempunyai mekanisme penentu pada keadaan 
kritis. Jika hipokampus memberikan sinyal bahwa masukan neuron tersebut bersifat penting, kemungkinan informasi tersebut akan disimpan menjadi ingatan. Dari hipokampus, menuju ke septum melalalui girus paraterminal kemudian masuk ke thalamus dan akhirnya ke hipotalamus. Di hipotalamus akan diolah dan disimpan sebagai memori. Dihipotalamus terdapat 2 mekanisme yang berperan dalam pembentukan kepribadian yaitu pusat ganjaran dan pusat hukuman yang terletak di nukle lateral dan ventromedial. Setelah diolah, maka hasil tersebut akan diinterpretasikan sebagai rasa senang, sedih, menarik diri, mengamuk, tidak percaya diri dan lain-lain sebagainya yang berhubungan dengan pola afektif seseorang (Guyton and Hall, 2014).

Jika secara auditorik maupun visual lebih banyak merangsang pusat ganjaran, maka akan terbentuk kepribadian dan pola afektif yang baik seperti rasa senang, percaya diri, kepuasan dan lain-lain. Jika ibu berada dalam kondisi tersebut, maka ia akan memberikan stimulasi yang baik kepada anaknya. Jika stimulasi yang diberikan baik, maka secara tidak langsung juga mempengaruhi perkembangan anaknya. Seperti halnya dengan mekanisme pembentukan pola afektif yang melibatkan system limbic, perkembangan anak juga dipengaruhi oleh factor eksternal. Apa yang dilihat dan didengar oleh anak akan diasosiasikan di otak. Yang dianggap penting akan disimpan dan bisa diinterpretasikan dalam pola afektif sehari-hari. Area asoisiasi adalah area yang penting karena area ini yang akan menerima dan menganalisis sinyal yang diterima. Area ini meliputi area asosiasi perieto-oksipital yang dapat menganalisis keserasian spasial tubuh, pemahaman bahasa, proses awal bahasa penglihatan (membaca) dan penamaan objek. Area asosiasi prefrontal yang penting dalam melakukan proses berpikir dalam benak pikiran, area brocha yang memiliki lintasan saraf untuk pembentukan kata, serta area asosiasi limbic yang berhubungan dengan tingkah laku, emosi dan motivasi. Jadi semakin baik stimulasi yang diberikan kepada anak, maka akan mempengarhui perkembangan anak kea rah yang lebiih baik (Guyton and Hall, 2014).

Teori ini sejalan dengan penelitian yang dilakukan oleh Harisson, mengenai sebuah intervensi untuk menguji model pembelajaran kepercayaan diri ibu yang masih remaja. Ditemukan bahwa terdapat hubungan antara kepercayaan diri ibu akan kemampuan merawat anaknya yang diperlukan untuk tahap tumbuh kembang anak dan hubungan ibu dan anak yang positif (Harrison, 2011). Penelitian lain yang dilakukan oleh Ozkan (2011), mengenai identitas ibu, pengembangan pendidikan dan pencapaian peran ibu dan persepsi bayi dari ibu primipara, dideteksi bahwa pelatihan pengembangan yang diberikan mengalami peningkatan dengan skala kepercayaan diri yang meningkat secara signifikan. Terdapat pula hubungan yang signifikan antara kepercayaan diri ibu dan perkembangan bayinya (Özkan \& Polat, 2011).

\section{SIMPULAN}

Kepercayaan diri ibu memiliki peranan penting dan sangat berpengaruh terhadap perkembangan anak usia pra sekolah.

\section{DAFTAR PUSTAKA}

Depkes. (2016). Profil Kesehatan RI 2015. In Profil Kesehatan Indonesia Tahun 2015. https://doi.org/10.1111/evo.12990

Dion, Y. (2013). Asuhan Keperawatan Keluarga Konsep Dan Praktik. In Asuhan Keperawatan Keluarga Konsep Dan Praktik.

Fajrah, R. (2017). Hubungan Pola Asuh Orang Tua dengan Perkembaangan Bahasa Anak Umur 4- 6 Tahun di PAUD Seruni dan Laut Biru Kelurahan Air Tawar.

Fasanghari, M., Kordi, M., \& Asgharipour, N. (2019). Effect of maternal role training program based on Mercer theory on maternal self-confidence of primiparous women with unplanned pregnancy. Journal of Education and Health Promotion. https://doi.org/10.4103/jehp.jehp_202_17

Guyton and Hall. (2014). Guyton dan Hall Buku Ajar Fisiologi Kedokteran. In Elsevier, Singapore. https://doi.org/10.1016/B978-14160-5452-8.00020-2

Harrison, S. L. (2011). An intervention to test the adolescent maternal confidence learning model.

Henney, S. M. (2016). The Relationship Between Personality and Parental Confidence in Mothers of School-Aged Children. SAGE Open,

6(3). https://doi.org/10.1177/2158244016659317

Hushmillo, M. , 28(2), 46-48. (2013). Maternal Role Attainment Theory. International Journal of Childbirth Education.

Husmillo, M. (2013). Maternal Role Attainment 
Theory. International Journal of Childbirth Education.

Kurniawati, E., Rosra, M., \& Utaminingsih, D. (2017). Hubungan antara Pola Asuh Orang Tua dengan Percaya Diri Siswa. ALIBKIN (Jurnal Bimbingan Konseling).

Maryam. (2017). Gambaran Tingkat Pendidikan dan Pola Asuh Ibu pada Anak Usia Dini di Gampong Pante Gajah Kecamatan Matang Glumpang Dua Kabupaten Bireuen. 3(2), 67-76. Retrieved from https://jurnal.arraniry.ac.id/index.php/equality/article/view/ $3443 / 2400$

Mercer, R. T. (2004). Becoming a mother versus maternal role attainment. Journal of Nursing Scholarship. https://doi.org/10.1111/j.1547-

5069.2004.04042.x

Mouton, B., \& Roskam, I. (2015). Confident Mothers, Easier Children: A Quasiexperimental Manipulation of Mothers' Self-efficacy. Journal of Child and Family Studies. https://doi.org/10.1007/s10826014-0051-0

Özkan, H., \& Polat, S. (2011). Maternal identity development education on maternity role attainment and my baby perception of primiparas. Asian Nursing Research. https://doi.org/10.1016/S19761317(11)60019-4

Saleh, A. (2011). Keperawatan anak terhadap pengetahuan, kemampuan praktik dan percaya diri ibu dalam menstimulasi tumbuh kembang bayi 0-6 bulan. Jurnal Ners, Vol. 6(No.2 Oktober), 175-186.

Shafaie, F. S., Mirghafourvand, M., \& Bagherinia, M. (2017). The association between maternal self-confidence and functional status in primiparous women during postpartum period, 2015-2016. International Journal of Women's Health and Reproduction Sciences, 5(3), 200-204. https://doi.org/10.15296/ijwhr.2017.36

Soetjiningsih. (2013). Tumbuh kembang janin dalam kandungan. In 2.

Vance, A. J., \& Brandon, D. H. (2017). Delineating among parenting confidence, parenting self-efficacy, and competence. Advances in Nursing Science.
https://doi.org/10.1097/ANS.000000000000 0179

Waqidil H, \& Ck, A. (2016). Hubunga AntaraTingkat Pendidikan Ibu dengan Perkembangan Balita Usia 3-5 Tahun (Suatu Studi diKelurahan Kadipaten Kecamatan Bojonegoro Kabupaten Bojonegoro Tahun 2014). Jurnal Bojonegoro Asuhan Kesehatan, 7(2), 2731.

Wong, D. L. (2003). Pedoman Klinis Keperawatan Pediatrik Edisi 4. In EGC. https://doi.org/10.2307/2404646 